\title{
Sleep, Serotonin, and Suicide
}

\author{
Jun Kohyama \\ Tokyo Bay Urayasu/Ichikawa Medical Center, Urayasu, Japan \\ Email: j-kohyama@jadecom.or.jp
}

Received October 3, 2012; revised October 23, 2012; accepted October 31, 2012

\begin{abstract}
The author hypothesizes that sleep loss associated with a decrease in serotonergic activity plays a significant role in attempted suicide. Recent research has emphasized the role of the economic recession on the occurrence of suicide, but with no attention paid to possible biological aspects. In this brief review, the association between sleep, the serotonergic system, and suicide is initially introduced. Then, with consideration of recent research, a hypothesis regarding the occurrence of suicide is proposed. Finally, based on that hypothesis, three factors possibly germane to reducing suicides (sufficient sleep duration, activation of the serotonergic system, and activation of the prefrontal cortex) are discussed.
\end{abstract}

Keywords: Economic Crisis; Prefrontal Cortex; C-Fiber; Yomikikase; Dakko

\section{Introduction}

Suicide is a complex behavior. Although depression is highly prevalent among people who commit suicide [1], many other risk factors have been implicated, including other health conditions (e.g., alcohol dependency, drug, dependency, cancer), sociodemographic features (e.g., being male, unmarried, unemployed), and climatic factors (e.g., cold weather, insufficient sunshine, snowfall) [2].

The author proposes that sleep loss may also play a significant role in attempted suicide, associated with a decrease in serotonin (5-hydroxytriptamine; 5-HT) activity $[3,4]$. A study emphasizing the role of the economic recession on the occurrence of suicide in the UK has been published [5]. However, that study lacks a biological viewpoint [6]. In this brief review, the association between sleep, 5-HT, and suicide is initially introduced. Then, a novel hypothesis regarding the occurrence of suicide will be proposed.

\section{Suicide and Serotonin}

It is difficult to establish direct links between suicide and specific neurotransmitters. However, norepinephrine, 5HT, dopamine [7], corticotrophin-releasing factor (CRF)/ cortisol, and retinoic acid [8] are reported to be involved in affective disorders including depression, which is highly prevalent among people who die as a result of suicide [1].

An association between suicide and hypofunction of the 5-HT system was proposed by several researchers in 1992. Therefore, all articles on suicide cited in this manu- script have been published in 1992 or after this year. Linnoila and Virkkunen [9] used the term 'low serotonin syndrome' as a clinical entity linked to violent suicide attempts. Mann and Arango [10] reported that alterations in the 5-HT system could be a risk factor for suicidal behavior. In 1995, Arango et al. [11] found an increase in 5-HT1A receptors in the ventrolateral prefrontal cortex (vlPFC) and a decrease in serotonin transporters in the vlPFC of suicide brains. The increase in 5-HT1A receptors in the vlPFC was interpreted as the result of up-regulation due to hypofunction of the 5-HT system. They concluded that suicide victims have an abnormality in the 5-HT system involving predominantly the vlPFC, and hypothesized that 5-HT dysfunction in this brain region contributes to the risk for suicidal behavior.

The vlPFC has been implicated in behavioral inhibittion and impulsivity [12,13]. Damage to this area causes an inability to change impulsive aggressive behavior, resulting in poor anger management [12]. If such behavior is directed inwardly instead of outwardly at others, the result may be suicide [12]. Although in mice, after the consumption of a moderate dose of alcohol, Chiavegatto et al. [14] reported a regionally selective and significant reduction of all 5-HT receptor subtype transcripts, except for 5-HT3, in the PFC of those who showed escalated aggression. Indeed, whether the anti- aggressive effects of 5-HT manipulations are associated with increased or decreased 5-HT transmission as a common neurobiological mechanism remains to be determined [14]. Leyton et al. [15] found that reduced 5-HT synthesis was exhibited in the PFC of individuals who had attempted suicide, compared with healthy controls. Hypofunction 
of the 5-HT system in the PFC is likely to be involved in attempted suicide.

Because 5-HT innervation to the PFC arises predominantly from the brainstem dorsal raphe nucleus (DRN), interest has been directed toward the DRN of suicide victims. Stockmeier et al. [16] reported more 5-HT1A binding in depressed suicides vs. controls in the ventrolateral and dorsal subnuclei of the DRN. The 5-HT1A receptor has been classified functionally as an inhibitory autoreceptor because the firing rate of 5-HT neurons in the DRN is inhibited by the direct application of a 5HT1A receptor agonist into the DRN [17]. Thus, Stockmeier et al. [16] interpreted the observed increase in presumably inhibitory 5-HT1A receptors in the DRN of depressed suicide victims as possibly providing pharmacological evidence for diminished activity of 5-HT neurons in those subjects. Consistent with that finding, Arango et al. [18] found higher 5-HT1A receptor crosssectional binding in the rostral DRN in depressed suicides compared with controls, and hypothesized that the rostral elevation of DRN 5-HT1A autoreceptor binding in depressed suicides was functionally related to their previous finding of more 5-HT1A binding in the ventral and lateral PFC [11]. They reasoned that an excess of autoreceptors would tend to lower the firing rate of 5-HT DRN neurons and reduce 5-HT release in the PFC, resulting in the up-regulation (increase) of 5-HT receptors in the PFC.

A potential role of the hypothalamic-pituitary-adrenal axis must be considered in the link between 5-HT and suicide, given that corticosteroids may play an important role in the relationship between stress, mood changes, and suicidal behavior via an interaction with 5-HT1A receptors [19]. It should be noted that CRF mobilizes the organism for response to stressors and also stimulates the central nervous system to respond to environmental challenges [20]. Waselus et al. [21] suggested that CRF has both direct and indirect effects on 5-HT neurons in the DRN and further implicated GABA as a primary mediator by which CRF and stressors alter the activity of the DRN-5-HT system. An indirect effect via stimulation of inhibitory GABA synaptic transmission may primarily produce the inhibition of 5-HT DRN neurons by CRF [22]. Neurosecretory neurons of the paraventricular nucleus (PVN) of the hypothalamus synthesize CRF [23]. However, it should be noted that the PVN projects only to a limited number of areas in the midbrain, including the DRN [24]. The source of CRF projected to the DRN remains to be determined.

Disturbances of the lateral orbito-prefrontal circuit have also been implicated in the emergence of aggressive behaviors [25]. Importantly, the 5-HT system is believed to activate this circuit [26]. Schweighofer et al. [27] ex- amined 5-HT conditions in relation to reward prediction with both short and long timeframes. They found an increase in the proportion of small reward choices, together with an increase in the rate of discounting of delayed rewards in the low 5-HT condition compared with the control and high 5-HT conditions. This suggests that low 5-HT levels are associated with impulsivity. Interestingly, links between impulsive personality characteristics and suicidal ideation and behavior have been reported [28]. Indeed, higher impulsivity levels, evaluated by multiple measures, were found to be related to a greater number of previous suicide attempts [29]. In addition, when subjects learned to act to obtain large future rewards while incurring small immediate losses, the dorsolateral PFC, inferior parietal cortex, DRN, and cerebellum were activated [30]. These findings indicate that decreased 5-HT activity, especially in the PFC, may play a role in suicidal behaviors.

\section{Serotonin and Sleep}

Research shows that chronically sleep-restricted rats have a blunted temperature response to direct stimulation of 5-HT1A receptors with a 1A agonist [31,32]. These experiments indicate that chronic sleep restriction causes a gradual and persistent desensitization of the 5-HT1A receptor system. Novati et al. [33] showed that chronic sleep restriction results in decreased sensitivity of 5HT1A receptors, assessed through pituitary response elicited by direct pharmacological stimulation with a 5HT1A agonist. It is well-known that levels of 5-HT are higher during wakefulness than during sleep. Novati et al. [33] raised the possibility that chronic sleep restriction and prolonged wakefulness lead to overstimulation and ultimately downregulation of 5-HT receptors. However, it should also be noted that acute sleep deprivation [34] or rapid eye movement (REM) sleep deprivation [35] can activate the 5-HT system.

5-HT activity is highest during wakefulness, decreases during non-REM sleep, and almost ceases during REM sleep [36]. During wakefulness, the 5-HT system is activated not only through exposure to morning light [37] but also through rhythmic movements, such as gait, chewing, and respiration [38]. It is widely recognized that poor sleep habits in humans can induce mood and motivetional disturbances, reduce attention, vigilance, and concentration, and increase daytime fatigue or sleepiness [39]. In addition, behaviorally-induced insufficient sleep syndrome is believed to be associated with the development of anergia, fatigue, and malaise [39]. When people are exhausted or sleepy, they are unlikely to perform sufficient physical activity to promote 5-HT activity to a desirable level. 


\section{Sleep and Suicide}

In addition to depression, poor sleep quality has been found to increase the risk for suicide [40]. Fujino et al. [41] showed that among 13,259 middle-aged adults, only difficulty maintaining sleep at baseline, compared with other sleep disturbances (e.g., difficulty initiating sleep, nonrestorative sleep) significantly predicted death by suicide 14 years later. Bernert and Joiner [42] cited these two studies and noted that depression was not accounted for when examining the association between sleep and completed suicide.

Several studies have examined the association between sleep disturbance and suicide rates in patients with a range of psychiatric disorders, including major depression, panic disorder, and schizophrenia [43-45]. Wojnar et al. [46] found that chronic sleep problems were associated with a greater risk of suicide. In addition, the investigators suggested that addressing sleep problems could reduce the risk of suicidal behavior.

In China [47], adolescents $(n=1362)$ attending school were surveyed with a self-administered questionnaire regarding sleep patterns, sleep problems, suicidal behavior, depressive symptoms, and demographic characteristics of family members. Logistic regression analyses revealed that sleeping $<8$ hours at night was associated with an increased risk of suicide attempts after adjusting for age, sex, and father's occupation. That study provided an important step in understanding the association between short sleep duration and suicide in adolescents. However, it should be emphasized that the direction of causality remains equivocal. As such, it is possible that suicidal thoughts may cause trouble sleeping rather than the converse.

In a study of sleep-deprived participants, Yoo et al. [48] reported a heightened hyper-limbic response to negative emotional stimuli in the amygdala, associated with reduced functional connectivity with the medial PFC. These findings lend further support to the notion that sleep loss is associated with irrational emotional behavior, including suicide.

Finally, recent meta-analysis using electronic databases for years 1966-2011 [49] supports that sleep disturbances in general, as well as insomnia and nightmares individually, appear to represent a risk factor for suicidal thoughts and behavior.

\section{Suicide and the Economy}

Suicides tend to increase in hard economic times, and there is evidence of a rising number in Europe [50] and in Greece [51] as people have lost their jobs and struggle to support themselves and their families, although an argument has been raised against a causal link [52]. Research by Barr et al. [5] suggests that the same pattern is now visible in the UK. The suicide rate had been dropping steadily in the UK for 20 years before the recession hit. However, in 2007-2008 it rose by $8 \%$ among men and $9 \%$ among women. Barr et al. investigated these statistics to establish whether the recession was the cause. They looked at information on suicides in 93 regions from the National Clinical and Health Outcomes Database for the decade from 2000-2010, and also examined, from the Office for National Statistics, the numbers of unemployed people claiming benefits. They found that the suicide rate among men rose by $1.4 \%$ for every $10 \%$ increase in unemployment. According to their analysis, between 2008 and 2010, 846 more men ended their life than would have been expected had the downward trend continued; the corresponding number for women was an extra 155 suicides. On average, male unemployment rose by $25.6 \%$ in each of those years, while the male suicide rate rose by $3.6 \%$ each year. When male employment rates rose briefly in 2010, the suicide rate dropped slightly. They concluded that unemployment is a particular risk factor for suicide.

A similar trend between suicide rate and unemployment rate as reported in Europe, Greece, and the UK was observed in Japan between 1988 and 1997, and from 1998 to 2000 [53,54]. However, neither the drop in unemployment rate (2004-2007) nor its increase (20072009) affected the number of suicides in Japan after 2000 (Figure 1) [53,54]. No one has been able to explain the observed relationship between rates of unemployment and suicide before 2000, and the lack of relationship after 2000. It should be noted that the annual number of suicide cases in Japan remained steady between 1980 and 1997, ranging between 20,000 and 25,000 individuals [53]. However, in 1998, this number increased to 32,863 and has remained over 30,000 for the past 14 years. Two possible explanations are proposed for this change in number of suicides in Japan and the lack of relationship between unemployment and suicides after 2000. One is that the unemployment rate does not affect the suicide rate when either the number of suicides or the unemployment rate increases beyond a certain level. The other possibility is that other factor(s) might affect the relationship between number of suicides and unemployment rate. Although further data from many other regions are needed to confirm these possibilities, in support of the latter, the author has observed unique characteristics in Japan.

\section{Sleep, Serotonin, and Suicide}

Japan is the only nation in the world in which $>25 \%$ of employed people are categorized as long-hour workers (working 50 hours or more per week) [55]. Conversely, labor productivity in Japan is below the average level of 30 industrialized nations, with the lowest value among 
developed nations [56]. This indicates that workers in Japan are likely to be sleep-deprived and work long hours. In addition, Japanese people devote little time to themselves [55]. As a result, Japan is one of the most sleepless countries, and average sleep duration has continuously decreased for at least the past 50 years. The average sleep duration of people in Japan age 10 years and older was 493 minutes in 1960 and 434 in 2010 [57]. It should be noted that the average sleep duration in 2009 reported by the OECD was 503 minutes in the UK and 470 minutes in Japan [55].

As discussed in previous sections, suicide and 5-HT, 5-HT and sleep, and sleep and suicide have mutual relationships. However, papers discussing suicide in relation to economic crisis have not referred to biological aspects. Here, it is hypothesized that financial crisis plays a significant role in the occurrence of suicide when sleep duration is preserved, while it fails to affect suicide occurrence when sleep duration decreases below a certain level, as determined by biological necessity. The biological necessity of sleep may be regulated by 5-HT activity. As mentioned, after 2000, neither the drop in rate of unemployment (2004-2007) nor its increase (20072009) affected the number of suicides in Japan (Figure 1). Sleep duration as measured after 2000 might have been at a level low enough that economic conditions did not exert an effect on occurrence of suicide. According to Figure 1, 442 minutes might be that value, although calibration is needed to compare that data with OECD data [55].

The schematic potential link between sleep and suicide with hypofunction of the 5-HT system is shown in Figure $2[1,4,10-15,20-22,26-29,31-33,37,38,43-45,47,48$, $8,59]$.

\section{Preventing Suicides}

According to the previous discussion, three factors are proposed relevant to preventing suicides: 1) sufficient

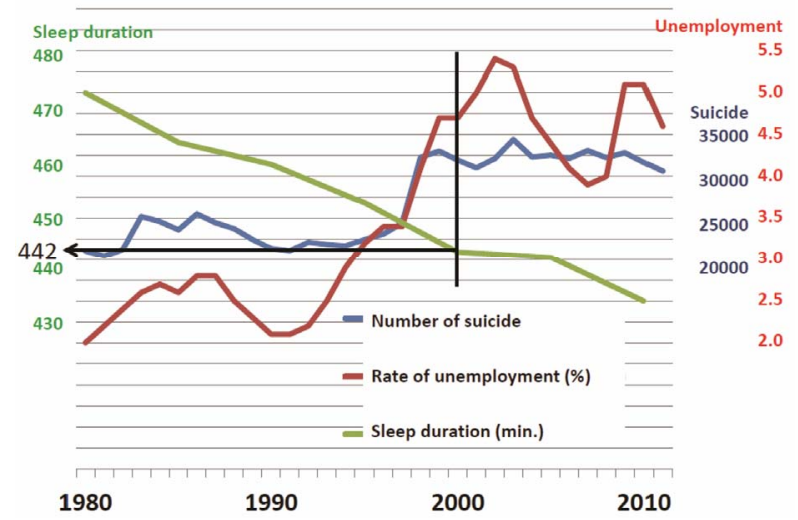

Figure 1. Change in number of suicides, unemployment rate, and sleep duration in Japan. sleep duration; 2) activation of 5-HT activity; and 3) activation of PFC.

Regarding sleep duration, it is difficult to specify a minimum requirement because sleep necessity can differ individually [60]. However, 442 minutes per night has been proposed from data obtained in Japan. Human beings are diurnally active; thus, their wakefulness should be highest in the morning [61]. If one feels no sleepiness in the morning, sleep duration is considered sufficient. Five basic principles are proposed for securing sufficient sleep (Table 1 [59]).

Young [62] proposed four nonpharmacologic methods of raising brain 5-HT: 1) positive (happy) mood induction; 2) exposure to bright light; 3) exercise; and 4) a tryptophan-enriched diet. Arita [12] proposed three factors to activate the 5-HT system: rhythmic movements, solar irradiation, and grooming. In addition, he posited that the time from birth to age 6 is an extremely important period for postnatal development of the brain 5-HT system. He stressed that rhythmic movements and solar irradiation from ages 3 - 6 years clearly activate 5-HT neurons. Finally, Arita noted that grooming is the third factor in activating 5-HT neurons. He argued that carrying a baby on the back or in the arms is regarded as a grooming action between mother and child, and these

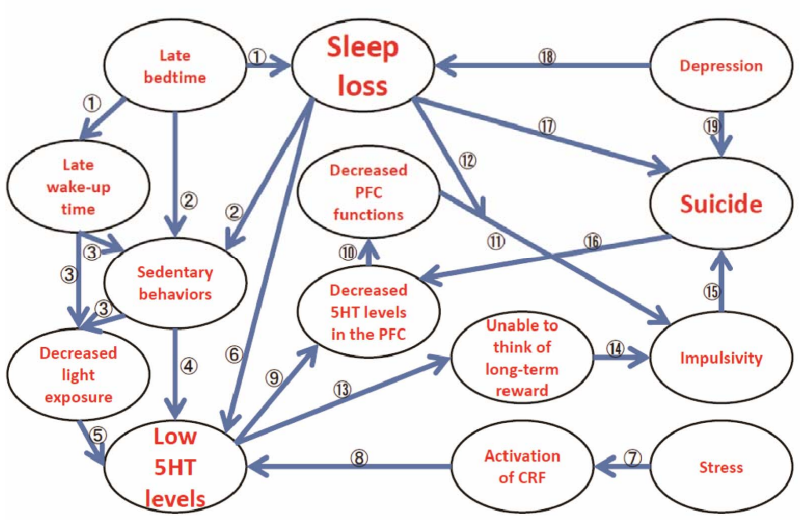

Figure 2. The schematic potential link between sleep and suicide with hypofunction of the serotonergic system. Arrows and supported references are as follows: (1) 58; (2) 59; (3) 12,13 ; (4) 38 ; (5) 37 ; (6) 31 - 33; (7) 20; (8) 21 , 22; (9) 10, 11; (10) 14 ; (11) 26 ; (12) 48 ; (13) 27 ; (14) 4 ; (15) 28,29 ; (16) 15 ; (17) 47 ; (18) 43 - 45; (19) 1 .

Table 1. Five principles of sleep health.

\footnotetext{
1. Increase exposure to morning light.

2. Engage in physical activity during the daytime.

3. Sleep in the dark during the night (i.e., turn off all artificial lighting).

4. Eat regular meals.

5. Avoid substances that disturb sleep (e.g., caffeine, alcohol, nicotine) and excessive media exposure (e.g., video games, computers, television).
} 
actions lead to activation of the brain 5-HT system in both mother and child. Interestingly, the level of 5-HT in the rat PFC during various types of grooming behaviors has been measured using the microdialysis method, and 5-HT levels were found to be significantly increased during induced grooming [63]. Atonia during non-REM sleep [64-66] has been preliminarily proposed as a way to assess brain 5-HT activity in humans [67].

Grooming might also be implicated in activity of the PFC. This behavior often involves tactile stimulation. In 2009, Löken et al. [68] reported that during soft brush stroking, low-threshold unmyelinated mechanoreceptors (C-tactile), but not myelinated afferents, responded most vigorously at intermediate brushing velocities $(1-10 \mathrm{~cm}$ /second), which were perceived by subjects as being the most pleasant. According to Nagi et al. [69], a class of unmyelinated fibers in the human hairy skin, known as C-tactile (CT) fibers, responds to innocuous mechanical stimulation. The response properties of CT fibers have been described using a limited range of stimuli-most notably slowly moving, low-force, mechanical stimuli such as finger stroking and soft brushing [68]. Neuroimaging studies have demonstrated that CT-mediated inputs project onto the insular cortex [70]. Recently, a direct contrast of the blood-oxygenation-level-dependent response to gentle brushing of the arm and palm revealed the involvement of a network of brain regions, in addition to the posterior insula, during CT-targeted affective touch to the arm [71]. This network included areas known to be involved in social perception and social cognition, including the right posterior superior temporal sulcus and the medial PFC/dorsoanterior cingulate cortex. Activation of CT fibers might activate the social brain [72] as well as the PFC. Although mutual involvement between the 5-HT system and this CT fiber-mediated sensory system has not been determined, favorable effects of a sort of grooming, or dakko, on hypoactivity of the 5-HT system have been proposed $[73,74]$. An older generation Japanese pediatrician [75] says that "Holding a baby in your arms ("dakko" in Japanese) is the most effective tranquilizer for the baby". Although therapeutic touch is now receiving attention as a method to manage anxiety disorders including depression [74], dakko is a typical daily behavior that involves direct contact between caretakers and youngsters.

In my previous paper [4], the potential role of yomikikase in activating the frontal brain area was introduced. Yomikikase is a Japanese word that means reading a book to another person. Yomi means to read, and kikase means to have someone listen. Yomikikase reportedly activates the limbic structures of child listeners and increases frontal cerebral blood flow, measured by functional near-infrared spectroscopy of readers [76,77]. Encouraging parents to engage in yomikikase might facili- tate them coming home earlier, which would reduce their working hours and potentially ameliorate problems associated with sleep loss, including the risk of suicide. However, the exact area in the PFC that is activated during yomikikase has not been clarified. Dara et al. [78] reported that the functional MRI signal changes in the dorsolateral part of the PFC correlated with working memory load. The effects of yomikikase or the training of working memory on the function of vlPFC are yet to be determined.

\section{Conclusion}

Social conditions indispensably affect mental status and might produce alterations in human central nervous system environments. Not only 5-HT but also social conditions can affect occurrence of suicide. In addition, 5-HT activity might be affected by the process of growing up. We should explore varied views in an effort to elucidate causes of suicide and develop ways to prevent this tragedy.

\section{REFERENCES}

[1] Y. Conwell, P. R. Duberstein, C. Cox, J. H. Herrmann, N. T. Forbes and E. D. Caine, "Relationships of Age and Axis I Diagnoses in Victims of Completed Suicide: A Psychological Autopsy Study," American Journal of Psychiatry, Vol. 153, No. 8, 1996, pp. 1001-1008.

[2] M. Nakao, T. Takeuchi and K. Yoshimasu, “A Proposed Approach to Suicide Prevention in Japan: The Use of SelfPerceived Symptoms as Indicators of Depression and Suicidal Ideation," Environmental Health and Preventive Medicine, Vol. 13, No. 6, 2008, pp. 313-321. doi:10.1007/s12199-008-0048-7

[3] J. Kohyama,” More Sleep Will Bring More Serotonin and Less Suicide in Japan,” Medical Hypotheses, Vol. 75, No. 3, 2010, pp. 340. doi:10.1016/j.mehy.2010.03.035

[4] J. Kohyama, "Sleep, Serotonin and Suicide in Japan,” Journal of Physiological Anthropology, Vol. 30, No. 1, 2011, pp. 1-8. doi:10.2114/jpa2.30.1

[5] B. Barr, D. Taylor-Robinson, A. Scott-Samuel, M. McKee and D. Stuckler, "Suicides Associated with the 2008-10 Economic Recession in England: Time Trend Analysis," British Medical Journal, Vol. 345, 2012, pp. e5142. doi:10.1136/bmj.e5142

[6] J. Kohyama, "Re: Suicides Associated with the 2008-10 Economic Recession in England: Time Trend Analysis," http://www.bmj.com/content/345/bmj.e5142/rr/598967

[7] D. Gunnell, D. Irvine, L. Wise, C. Davies and R. M. Martin, "Varenicline and Suicidal Behaviour: A Cohort Study Based on Data from the General Practice Research Database,” British Medical Journal, Vol. 339, 2009, pp. 3805. doi:10.1136/bmj.b3805

[8] J. D. Bremner and P. McCaffery,” The Neurobiology of Retinoic Acid in Affective Disorders," Progress in NeuroPsychopharmacology and Biological Psychiatry, Vol. 32, 
No. 2, 2008, pp. 315-331. doi:10.1016/j.pnpbp.2007.07.001

[9] V. M. Linnoila and M. Virkkunen, "Aggression, Suicidality, and Serotonin,” Journal of Clinical Psychiatry, Vol. 53, Suppl. 10, 1992, pp. 46-51.

[10] J. J. Mann and V. Arango, "Integration of Neurobiology and Psychopathology in a Unified Model of Suicidal Behavior,” Journal of Clinical Psychopharmacology, Vol. 12, Suppl. 2, 1992, pp. 2S-7S.

[11] V. Arango, M. D. Underwood, A. V. Gubbi and J. J. Mann, "Localized Alterations in Pre- and Postsynaptic Serotonin Binding Sites in the Ventrolateral Prefrontal Cortex of Suicide Victims,” Brain Research, Vol. 688, No. 1-2, 1995, pp. 121-133. doi:10.1016/0006-8993(95)00523-S

[12] H. Arita, "Brain Mechanisms of Poor Anger Management," Japan Medical Association Journal, Vol. 52, No. 3, 2009, pp.184-90.

[13] H. Arita, "The Neuroscience of Suicide (in Japanese)," Brain and Nerve, Vol. 64, 2012, No. 8, pp. 929-935.

[14] S. Chiavegatto, I. M. Quadros, G. Ambar and K. A. Miczek, "Individual Vulnerability to Escalated Aggressive Behavior by a Low Dose of Alcohol: Decreased Serotonin Receptor mRNA in the Prefrontal Cortex of Male Mice," Genes, Brain and Behavior, Vol. 9, No. 1, 2010, pp. 110-119. doi:10.1111/j.1601-183X.2009.00544.X

[15] M. Leyton, V. Paquette, P. Gravel, P. Rosa-Neto, F. Weston, M. Diksic and C. Benkelfat, "Alpha- $\left[{ }^{11} \mathrm{C}\right]$ methyl-Ltryptophan Trapping in the Orbital and Ventral Medial Prefrontal Cortex of Suicide Attempters," European Neuropsychopharmacology, Vol. 16, No. 3, 2006, 220-223. doi:10.1016/j.euroneuro.2005.09.006

[16] C. A. Stockmeier, L. A. Shapiro, G. E. Dilley, T. N. Kolli, L. Friedman and G. Rajkowska, "Increase in Serotonin1A Autoreceptors in the Midbrain of Suicide Victims with Major Depression-Postmortem Evidence for Decreased Serotonin Activity,” Journal of Neuroscience, Vol. 18, No. 18, 1998, pp. 7394-7401.

[17] J. S. Sprouse and G. K. Aghajanian, “(-)-Propranolol Blocks the Inhibition of Serotonergic Dorsal Raphe Cell Firing by 5-HT1A Selective Agonists," European Journal of Pharmacology, Vol. 128, No. 3, 1986, pp. 295-298. doi:10.1016/0014-2999(86)90782-X

[18] M. Boldrini, M. D. Underwood, J. J. Mann and V. Arango, "Serotonin-1A Autoreceptor Binding in the Dorsal Raphe Nucleus of Depressed Suicides," Journal of Psychiatric Research, Vol. 42, No. 6, 2008, pp. 433-442. doi:10.1016/j.jpsychires.2007.05.004

[19] M. Pompili, G. Serafini, M. Innamorati, A. M. MöllerLeimkühler, G. Giupponi, P. Girardi, R. Tatarelli and D. Lester, "The Hypothalamic-Pituitary-Adrenal Axis and Serotonin Abnormalities: A Selective Overview for the Implications of Suicide Prevention," European Archives of Psychiatry and Clinical Neuroscience, Vol. 260, No. 8, 2010, pp. 583-600. doi:10.1007/s00406-010-0108-Z

[20] K. M. Carlin, W. W. Vale and T. L. Bale, "Vital Functions of Corticotropin-Releasing Factor (CRF) Pathways in Maintenance and Regulation of Energy Homeostasis," Proceedings of the National Academy of Sciences of the United States of America, Vol. 103, No. 9, 2006, pp. 3462-
3467. doi:10.1073/pnas.0511320103

[21] M. Waselus, R. J. Valentino and E. J. Van Bockstaele, "Ultrastructural Evidence for a Role of Gamma-Aminobutyric Acid in Mediating the Effects of CorticotropinReleasing Factor on the Rat Dorsal Raphe Serotonin System,” Journal of Comparative Neurology, Vol. 482, No. 2, 2005, pp. 155-165. doi:10.1002/cne.20360

[22] L. G. Kirby, E. Freeman-Daniels, J. C. Lemos, J. D. Nunan, C. Lamy, A. Akanwa and S. G. Beck, "Corticotropin-Releasing Factor Increases GABA Synaptic Activity and Induces Inward Current in 5-Hydroxytryptamine Dorsal Raphe Neurons,” The Journal of Neuroscience, Vol. 28, No. 48, 2008, pp. 12927-12937. doi:10.1523/JNEUROSCI.2887-08.2008

[23] E. G. Meloni, A. V. Jackson, B. M. Cohen and W. A. Carlezon, Jr, "Corticotropin-Releasing Factor from the Rat Brain Measured by Protein Immunoblot,” Peptides, Vol. 26, No. 11, 2005, pp. 2252-2256. doi:10.1016/j.peptides.2005.04.011

[24] J. C. Geerling, J.-W. Shin, P. C. Chimenti and A. D. Loewy, "Paraventricular Hypothalamic Nucleus: Axonal Projections to the Brainstem," Journal of Comparative Neurology, Vol. 518, No. 9, 2010, pp. 1460-1499. doi:10.1002/cne.22283

[25] G. E. Alexander, M. R. DeLong and P. L. Strick, "Parallel Organization of Functionally Segregated Circuits Linking Basal Ganglia and Cortex,” Annual Review of Neuroscience, Vol. 9, 1986, pp. 357-381. doi:10.1146/annurev.ne.09.030186.002041

[26] S. Tekin and J. L. Cummings, "Frontal-Subcortical Neuronal Circuits and Clinical Neuropsychiatry: An Update," Journal of Psychosomatic Research, Vol. 53, No. 2, 2002, pp. 647-654. doi:10.1016/S0022-3999(02)00428-2

[27] N. Schweighofer, M. Bertin, K. Shishida, Y. Okamoto, S. C. Tanaka, S. Yamawaki and K. Doya, "Low-Serotonin Levels Increase Delayed Reward Discounting in $\mathrm{Hu}-$ mans,” The Journal of Neuroscience, Vol. 28, No. 17, 2008, pp. 4528-4532. doi:10.1523/JNEUROSCI.4982-07.2008

[28] A. R. Smith, T. K. Witte, N. E. Teale, S. L. King, T. W. Bender and T. E. Joiner, "Revisiting Impulsivity in Suicide: Implications for Civil Liability of Third Parties," Behavioral Sciences \& the Law, Vol. 26, No. 6, 2008, pp. 779-797. doi:10.1002/bsl.848

[29] D. M. Dougherty, C. W. Mathias, D. M. Marsh, T. D. Papageorgiou, A. C. Swann and F. G. Moeller, "Laboratory Measured Behavioral Impulsivity Relates to Suicide Attempt History," Suicide and Life-Threatening Behavior, Vol. 34, No. 4, 2004, pp. 374-385. doi:10.1521/suli.34.4.374.53738

[30] S. C. Tanaka, K. Doya, G. Okada, K. Ueda, Y. Okamoto and S. Yamawaki, " Prediction of Immediate and Future Rewards Differentially Recruits Cortico-Basal Ganglia Loops,” Nature Neuroscience, Vol. 7, No. 8, 2004, pp. 887-893. doi:10.1038/nn1279

[31] V. Roman, I. Walstra, P. G. Luiten and P. Meerlo, “Too Little Sleep Gradually Desensitizes the Serotonin 1A Receptor System,” Sleep, Vol. 28, No. 12, 2005, pp. 15051510.

[32] V. Roman, R. Hagewoud, P. G. M. Luiten and P. Meerlo, 
"Differential Effects of Chronic Partial Sleep Deprivation and Stress on Serotonin-1A and Muscarinic Acetylcholine Receptor Sensitivity,” Journal of Sleep Research, Vol. 15, No. 4, 2006, pp. 386-394. doi:10.1111/j.1365-2869.2006.00555.x

[33] A. Novati, V. Roman, T. Cetin, R. Hagewoud, J. A. den Boer, P. G. Luiten and P. Meerlo, "Chronically Restricted Sleep Leads to Depression-Like Changes in Neurotransmitter Receptor Sensitivity and Neuroendocrine Stress Reactivity in Rats,” Sleep, Vol. 31, No. 11, 2008, pp. 15791585.

[34] J. P. Gardner, C. A. Fornal and B. L. Jacobs, "Effects of Sleep Deprivation on Serotonergic Neuronal Activity in the Dorsal Raphe Nucleus of the Freely Moving Cat,” Neuropsychopharmacology, Vol. 17, No. 2, 1997, pp. 72-81. doi:10.1016/S0893-133X(97)00025-0

[35] R. B. Machado, S. Tufik and D. Suchecki, "Chronic Stress during Paradoxical Sleep Deprivation Increases Paradoxical Sleep Rebound: Association with Prolactin Plasma Levels and Brain Serotonin Content," Psychoneuroendocrinology, Vol. 33, No. 9, 2008, pp. 1211-1224. doi:10.1016/j.psyneuen.2008.06.007

[36] C. M. Portas, B. Bjorvatn and R. Ursin, "Serotonin and the Sleep/Wake Cycle: Special Emphasis on Microdialysis Studies,” Progress in Neurobiology, Vol. 60, No. 1, 2000, pp. 13-35. doi:10.1016/S0301-0082(98)00097-5

[37] F. R. Cagampang, S. Yamazaki, Y. Otori and S. I. Inouye, "Serotonin in the Raphe Nuclei: Regulation by Light and an Endogenous Pacemaker,” Neuroreport, Vol. 5, No. 1, 1993, pp. 49-52. doi:10.1097/00001756-199310000-00012

[38] B. L. Jacobs and E. C. Azmitia, "Structure and Function of the Brain Serotonin System," Physiological Reviews, Vol. 72, No. 1, 1992, pp. 165-229

[39] American Academy of Sleep Medicine, "The International Classification of Sleep Disorder,” 2nd Edition, American Academy of Sleep Medicine, Westchester, 2005.

[40] C. L. Turvey, Y. Conwell, M. P. Jones, C. Phillips, E. Simonsick, J. L. Pearson and R. Wallace, "Risk Factors for Late-Life Suicide: A Prospective, Community-Based Study,” American Journal of Geriatric Psychiatry, Vol. 10, No. 4, 2002, pp. 398-406. doi:10.1176/appi.ajgp.10.4.398

[41] Y. Fujino, T. Mizoue, N. Tokui and T. Yoshimura, "Prospective Cohort Study of Stress, Life Satisfaction, SelfRated Health, Insomnia, and Suicide Death in Japan,” Suicide and Life-Threatening Behavior, Vol. 35, No. 2, 2005, pp. 227-237. doi:10.1521/suli.35.2.227.62876

[42] R. A. Bernert and T. E. Joiner, "Sleep Disturbances and Suicide Risk: A Review of the Literature,” Neuropsychiatric disease and treatment, Vol. 3, No. 6, 2007, pp. 735743

[43] M. Y. Agargun, A. S. Cilli, H. Kara, N. Tarhan, N. T. Kincir and H. Oz, "Repetitive and Frightening Dreams and Suicidal Behavior in Patients with Major Depression,” Comprehensive Psychiatry, Vol. 39, No. 4, 1998, pp. 198-202. doi:10.1016/S0010-440X(98)90060-8

[44] M. Y. Agargun and H. Kara, "Recurrent Sleep Panic, Insomnia, and Suicidal Behavior in Patients with Panic Disorder,” Comprehensive Psychiatry, Vol. 39, No. 3, 1998, pp. 149-151. doi:10.1016/S0010-440X(98)90074-8

[45] R. K. Singareddy and R. Balon, "Sleep and Suicide in Psychiatric Patients,” Annals of Clinical Psychiatry, Vol. 13, No. 2, 2001, pp. 93-101. doi:10.3109/10401230109148954

[46] M. Wojnar, M. A. Ilgen, J. Wojnar, R. J. McCammon, M. Valenstein and K. J. Brower, "Sleep Problems and Suicidality in the National Comorbidity Survey Replication," Journal of Psychiatric Research, Vol. 43, No. 5, 2009, pp. 526-531. doi:10.1016/j.jpsychires.2008.07.006

[47] X. Liu, “Sleep and Adolescent Suicidal Behavior," Sleep, Vol. 27, No. 7, 2004, pp. 1351-1358.

[48] S. S. Yoo, N. Gujar, P. Hu, F. A. Jolesz and M. P. Walker, "The Human Emotional Brain without Sleep-A Prefrontal Amygdala Disconnect. Sleep-Deprivation Causes an Emotional Brain 'Disconnect'," Current Biology, Vol. 17, No. 20, 2007, pp. R877-R878. doi:10.1016/j.cub.2007.08.007

[49] W. R. Pigeon, M. Pinquart and K. Conner, "Meta-Analysis of Sleep Disturbance and Suicidal Thoughts and Behavior," Journal of Clinical Psychiatry, Vol. 73, No. 9. pp. e1160-e1167. doi:10.4088/JCP.11r07586

[50] D. Stuckler, S. Basu, M. Suhrcke, A. Coutts and M. McKee, "Effects of the 2008 Recession on Health: A First Look at European Data,” Lancet, Vol. 378, No. 9786, 2011, pp. 124-125. doi:10.1016/S0140-6736(11)61079-9

[51] M. Economou, M. Madianos, C. Theleritis, L. E. Peppou and C. N. Stefanis, "Increased Suicidality amid Economic Crisis in Greece,” Lancet, Vol. 378, No. 9801, 2011, p. 1459. doi:10.1016/S0140-6736(11)61638-3

[52] K. N. Fountoulakis, I. A. Grammatikopoulos, S. A. Koupidis, M. Siamouli and P. N. Theodorakis, "Health and the Financial Crisis in Greece,” Lancet, Vol. 379, No. 9820, 2012, pp. 1001-1002. doi:10.1016/S0140-6736(12)60422-X

[53] Y. Honkawa, “Number of Suicide by Occupation,” 2012, http://www2.ttcn.ne.jp/honkawa/2740-2.html

[54] Y. Honkawa, “Alteration of Rate of Unemployed,” 2012. http://www2.ttcn.ne.jp/honkawa/3080.html

[55] OECD, “Better Life Index,” 2012. http://www.oecdbetterlifeindex.org/

[56] Japan Productivity Center, "International Comparison on Labor Productivity,” 2011.

http://www.jpc-net.jp/intl_comparison/intl_comparison_2 011.pdf

[57] Broadcasting Culture Research Institute, "Basic Survey on Social Life in Japan, 2010,” 2011.

http://www.nhk.or.jp/bunken/summary/yoron/lifetime/pdf /110223.pdf

[58] J. Kohyama, T. Shiiki, J. O. Sugimoto and T. Hasegawa, "Potentially Harmful Sleep Habits of 3-Year-Old Children in Japan,” Journal of Develomental and Behavioral Pediatrics, Vol. 23, No. 2, 2002, pp. 67-70. doi:10.1097/00004703-200204000-00001

[59] J. Kohyama, "Neurochemical and Neuropharmacological Aspects of Circadian Disruptions: An Introduction to Asynchronization," Current Neuropharmacology, Vol. 9, No. 2, 2011, pp. 330-341. 


\section{doi:10.2174/157015911795596522}

[60] M. A. Carskadon and W. C. Dement, "Normal Human Sleep: An Overview,” In: M. H. Kryger, T. Roth and W. C. Dement, Eds., Principles and Practice of Sleep Medicine, Elsevier Saunders, Philadelphia, 2005, pp. 13-23. doi:10.1016/B0-72-160797-7/50009-4

[61] P. Lavie, "Ultradian Rhythms: Gates of Sleep and Wakefulness,” In: H. Schulz and P. Lavie, Eds., Ultradian Rhythms in Physiology and Behavior, Springer-Verlag, New York, 1985, pp. 148-164. doi:10.1007/978-3-642-70483-3_11

[62] S. N. Young, "How to Increase Serotonin in the Human Brain without Drugs," Journal of Psychiatry and Neuroscience, Vol. 32, No. 6, 2007, pp. 394-399.

[63] N. Shiota, N. Narikiyo, A. Masuda, T. Tsuruoka and S. Aou, "Neural Mechanisms of Self-Care Behavior: Grooming-Related Changes in Serotonin and Dopamine in the Rat Prefrontal Cortex," Journal of Nursing Research, Vol. 6, No. 1, 2008, pp. 1-8.

[64] O. Petre-Quadens, “Sleep in Mental Retardation,” In: C. D. Clemente, D. P. Purpura and F. E. Mayer, Eds., Sleep and Maturing Nervous System, Academic Press, New York, 1972, pp. 384-417.

[65] L. Curzi-Dascalova, "Developmental Trend of Sleep Characteristics in Premature and Full-Term Newborns,” In: O. P. Mathew, Ed., Respiratory Control and Disorders in the Newborn, Marcel Dekker, New York, 2002, pp. 149-181.

[66] E. Werth, P. Achermann and A. A. Borbely, "Selective REM Sleep Deprivation during Daytime II. Muscle Atonia in Non-REM Sleep,” American Journal of Physiology, Vol. 283, No. 2, 2002, pp. R527-R532.

[67] J. Kohyama, "Pathophysiology of West Syndrome-Consideration from Sleep Studies,” In: S. M. Benjamin, Ed., Focus of Epilepsy Research, Nova Science Publishers, New York, 2004, pp. 79-104.

[68] L. S. Löken, J. Wessberg, I. Morrison, F. McGlone and H. Olausson, "Coding of Pleasant Touch by Unmyelinated Afferents in Humans," Nature Neuroscience, Vol. 12, No. 5, 2009, pp. 547-548. doi:10.1038/nn.2312

[69] S. S. Nagi, T. K. Rubin, D. K. Chelvanayagam, V. G.
Macefield and D. A. Mahns, "Allodynia Mediated by CTactile Afferents in Human Hairy Skin,” Journal of Physiology, Vol. 589, No. 16, 2011, pp. 4065-4075.

[70] H. Olausson, Y. Lamarre, H. Backlund, C. Morin, B. G. Wallin, G. Starck, S. Ekholm, I. Strigo, K. Worsley, A. B. Vallbo and M. C. Bushnell, "Unmyelinated Tactile Afferents Signal Touch and Project to Insular Cortex,” $\mathrm{Na}$ ture Neuroscience, Vol. 5, No. 9, 2002, pp. 900-904. doi:10.1038/nn896

[71] I. Gordon, A. C. Voos, R. H. Bennett, D. Z. Bolling, K. A. Pelphrey and M. D. Kaiser, "Brain Mechanisms for Processing Affective Touch,” Human Brain Mapping, in press.

[72] I. Morrison, L. S. Löken and H. Olausson, "The Skin as a Social Organ,” Experimental Brain Research, Vol. 204, No. 3, 2010, pp. 305-314. doi:10.1007/s00221-009-2007-y

[73] J. Kohyama, “A Newly Proposed Disease Condition Produced by Light Exposure during Night: Asynchronization,” Brain and Development, Vol. 31, No. 4, 2009, pp. 255-273. doi:10.1016/j.braindev.2008.07.006

[74] J. Robinson, F. C. Biley and H. Dolk, “Therapeutic Touch for Anxiety Disorders," Cochrane Database of Systematic Reviews, 2007.

[75] H. Kawai, “A Mother and Baby Notebook,” 2002 Version, Proceedings of the 111th Annual Meeting of the Japan Pediatric Society, Tokyo, 25-27 April 2008, p. 144.

[76] T. Haji, N. Tajima, M. Matsumoto, T. Sasaki, M. Hachisuka, M. Aihara and M. Taira, "Cortical Activations of Mother and Child during Reading to Child-Yomikikase: An fNIRS Study," Proceeding of the 84th Congress of the Physiological Society of Japan, Osaka, 20-22 March 2007, p. 169.

[77] M. Taira, "Yomikikasehakokorononounitodoku (in Japanese),” Kumon Publisher, Tokyo, 2009.

[78] D. S. Manoach, G. Schlaug, B. Siewert, D. G. Darby, B. M. Bly, A. Benfield, R. R. Edelman and S. Warach, "Prefrontal Cortex fMRI Signal Changes Are Correlated with Working Memory Load,” Neuroreport, Vol. 8, No. 2, 1997, pp. 545-549. doi:10.1097/00001756-199701200-00033 